Revista do SELL

v. 6 , no. 3

ISSN: $1983-3873$

\title{
A ABORDAGEM DA ORALIDADE NO LIVRO DIDÁTICO DE LÍNGUA PORTUGUESA: PROGRESSO OU DECLÍNIO?
}

THE ORALITY APPROACH IN THE PORTUGUESE LANGUAGE TEXTBOOK:

PROGRESS OR DECLINE?

\author{
Marcus Garcia de Sene \\ Universidade Estadual Paulista
}

\begin{abstract}
RESUMO: Devido ao amplo espaço que a tradição escolar reserva à escrita, o trabalho com a oralidade em sala de aula continua sendo pouco abordado ou recebe um tratamento controverso por parte dos professores de língua materna. Em relação às produções acadêmicas que envolvem as práticas de leitura e escrita, por exemplo, a oralidade no ensino tem recebido pouco atenção e, muitas das vezes, esquecida como uma importante ferramenta para socialização humana e na formação para plena participação cidadã. No contexto escolar, a necessidade de um trabalho sistematizado com gêneros orais para ampliação das capacidades de linguagem tem sido defendida por diversos autores como Marcuschi $(2001,2003)$. Sendo assim, este trabalho objetiva analisar dois livros aprovados pelo PNLD 2017 e distribuídos para determinadas escolas brasileiras. O intuito é verificar qual o tratamento está sendo dado ao eixo oralidade no livro didático e, consequentemente, aos gêneros orais e a relação entre oralidade-escrita. Os dados apresentaram que, embora houve uma reformulação dos critérios do eixo oralidade e escrita ao longo dos anos de existência do PNLD, em vez de abarcar elementos mais detalhados e específicos, acabou por reduzir a exigência destinada à reflexão sobre as relações entre oralidade-escrita e os gêneros orais.
\end{abstract}

PALAVRAS-CHAVE: Oralidade e Escrita; Livro didático; Ensino de Língua Portuguesa.

ABSTRACT: Due to the vast importance that the school tradition reserves for the writing, the work with the oral tradition in the classroom, is still little approached or receives a controversial treatment on the part of the mother tongue teachers. In relation to academic productions involving reading and writing, the orality in teaching, for example, has received low attention and is often forgotten as an important tool for human socialization and training for full citizen participation. In the school context, the need for systematized work with oral genres to expand language skills has been advocated by several authors Marcuschi $(2001,2003)$. From this, this work aims to analyze two books approved by PNLD/2017 and distributed to certain Brazilian schools. The purpose is to verify what treatment is being given to the orality axis in the textbook and, consequently, to oral genres and the relation between orality and writing. The data show that, although there was a reformulation of the criteria of the oral or written axis throughout the years of the PNLD,instead of covering more detailed and specific elements, it ended up reducing the requirement for reflection on relations Between orality-writing and oral genres.

KEYWORDS: Orality and Writing; Teaching book; Teaching Language. 


\section{Revista do SELL \\ v. 6 , no. 3 \\ ISSN: $1983-3873$}

\section{CONSIDERAÇÕES INICIAIS}

Muito embora a língua oral seja anterior à escrita, essa acaba por constituir-se como o centro do estudo da língua, uma vez que adquiriu, rapidamente, o status de avanço tecnológico que permitiu o domínio de atividades cognitivas. Aliado a isso, a invenção da escrita, como possibilidade de armazenamento e transmissão de informações, ganhou força com o processo de ensino-aprendizagem de Língua Portuguesa (LP) centrada no ensino de gramatica normativa, tendo como ensino de língua como sinônimo de gramática e escrita. Contudo, "a escrita é um fato histórico e deve ser tratado como tal e não como um bem natural" (MARCUSHI, 2010, p. 24).

Essa falsa supremacia em relação à escrita tem contribuído para o afastamento da oralidade em sala de aula e, quando não está distante dos bancos escolares, acaba recebendo o valor inverso a sua importância (MARCUSCHI, 2001). Constata-se que, na grande maioria das vezes, quando o professor de língua recorre a modalidade oral da língua, acaba por se limitar a utilização de recursos da expressão oral como vetor para o entendimento do texto escrito, quando não leitura em voz alta. A ausência de práticas não consciente com a oralidade tem se refletido nas produções escritas dos alunos que, cada vez mais, apresentam hábitos da fala que são transpostos para e escrita, conforme já indicado por alguns linguistas (ASSUNÇÃO et al 2015; SOUZA, 2015, GARCIA, 2016, GARCIA e ORANGES, 2017).

No tocante ao ensino da oralidade, os Parâmetros Curriculares Nacionais (BRASIL, 1998), há algum tempo, vem indicando a necessidade da escola em instrumentalizar o aluno para o domínio da linguagem oral, reconhecendo, sobretudo, que a escola deve propiciar um ambiente que respeite a diversidade linguística, mas tendo o dever de ensinar-lhe os usos da língua adequado a diferentes situações comunicacionais. Coadunamos com a afirmação de Castilho (2005) quando lembra que a:

oralidade abria caminhos de muito interesse para uma nação pouco letrada como a nossa. Por meio da língua falada, poderíamos chegar à língua escrita, num percurso mais proveitoso, porque fundamentado no que o aluno já sabe para chegar a domínios que ele não conhece (CASTILHO, 2005, p. 2)

Partindo dessas reflexões, sabendo da importância do tratamento da oralidade no ensino de língua (MARCUSCHI, 2001; LEAL e GOIS, 2012; GARCIA e ORANGES, 2016) e que um dos recursos mais mobilizados em sala de aula na disciplina de LP é o livro 


\section{Revista do SELL}

v. 6 , no. 3

ISSN: $1983-3873$

didático, que o estudo em pauta objetiva-se analisar dois livros didáticos de língua portuguesa, de coleções diferentes, destinado ao público do 6ำ ano e aprovados no Plano Nacional do Livro Didático - PNLD (2017), sobre o tratamento que recebe a oralidade e, ainda, verificarmos se houve um progresso ou declínio em relação ao tratamento do tema.

Para iniciar esta discussão, opta-se por refletir, no preâmbulo, sobre a oralidade e o ensino de Língua Portuguesa. Em seguida, discutiremos sobre o que apregoam os PCN, no que diz respeito a oralidade. Posteriormente, põem-se em pauta a análise dos livros didáticos em relação ao tratamento da oralidade. Por fim, as considerações finais.

\section{ORALIDADE E ENSINO DE LÍNGUA PORTUGUESA}

O ensino de língua portuguesa, como disciplina obrigatória no Brasil, se deu a partir de 1759, com a reforma pombalina, seguindo o modelo de estudo da língua latina e destinado à gramática, retórica e poética (SOARES, 1998). A disciplina denominada Português, passou a existir nas últimas décadas do século XIX. Soares (1998), a esse respeito, relembra que o estudo da língua serviria para a compreensão e imitação dos autores portugueses e brasileiros da época; para tanto, as antologias escolares, que serviam como manuais, pautavam-se no conhecimento e reconhecimento da língua.

Com a democratização escolar, o foco do ensino passa a ser outro. Em meados da década de 60, tendo como base os pressupostos de Jakobson e Saussure, o ensino da língua passa a ter como objetivo "o desenvolvimento e aperfeiçoamento do comportamento do aluno como emissor-codificador e como recebedor-decodificador de mensagens e pela utilização e compreensão de códigos diversos verbais e não-verbais" (SOARES, 1998, p.57).

Observa-se, portanto, uma alteração no foco em que o ensino passa a se preocupar mais com aspectos relacionados a habilidades de expressão e compreensão de mensagens. Para isso, o foco recaí no código, a gramática passa a ser descritiva com fixação de nomenclatura e suas classificações. O estudo pleno da gramática é, em tese, substituído pela teoria da comunicação, e a leitura é baseada na decodificação de signos.

Essa perspectiva de língua como instrumento de comunicação persistiu até meados da década de 80, quando foram levantados questionamentos sobre a ineficiência do método, o que resultou na crise da linguagem (SOARES, 1998). Assim, dando um salto após a rediscussão de questões envolvendo os métodos, observamos "uma 


\section{Revista do SELL \\ v. 6 , no. 3 \\ ISSN: $1983-3873$}

redemocratização do país e, com ela, a inserção de novas correntes teóricas como as da Sociolinguística, Psicolinguística, Linguística Textual, Pragmática e Análise do Discurso". (SILVA e LUNA, 2014, p. 31).

Essa correntes permitiram reconfigurar o foco de estudo de ensino para aprendizagem e, a partir disso, desenvolveu-se uma nova perspectiva linguística, com a qual "vê a língua como enunciação, discurso, não apenas como comunicação, que, portanto,inclui as relações da língua com aqueles que a utilizam, com o contexto em que é utilizada, com as condições sociais e históricas de sua utilização" (SOARES, 1998, p. 59).

Nessa perspectiva, a língua é um sistema heterogêneo e a oralidade passa a ganhar um espaço, ainda vago, pelo menos nos documentos oficiais que regem a educação. Os Parâmetros Curriculares Nacionais, por exemplo, propõem que o ensino da língua oral e escrita, aliado a reflexões sobre a língua e linguagem, sejam eixos básicos de ensino. (BRASIL, 1998). Contudo, a tradição grafocêntrica continua sendo seguida, ou seja, a oralidade deixa de ser uma habilidade a ser desenvolvida na escola em razão de acreditarem que os estudantes chegam ao ambiente escolar com o total domínio da fala.

Assim, as práticas de oralidade na escola são, contudo, quase inexistentes (MARCUSCHI, 2003; MAGALHÃES, 2005/2006). Os estudos de Marcuschi (2001), por exemplo, reforçam a ideia de que existe uma doutrina escolar que define a escrita como superior a fala e se configura como um método recorrente e dicotômico no ensino de língua, atribuindo status elevado a escrita; todavia, o linguista desconstrói essa perspectiva quando afirma que:

Assim como a fala não apresenta propriedades intrínsecas negativas, também a escrita não tem propriedades intrínsecas privilegiadas. São modos de representação cognitiva e social que se revelam em práticas específicas. Postular algum tipo de supremacia ou superioridade de algumas das duas modalidades seria uma visão equivocada, pois não se pode afirmar que a fala é superior a escrita ou vice-versa (MARCUSCHI, 2001, p.35)

Essa supremacia acaba se refletindo nos livros didáticos que, pouquíssimas vezes, instiga o professor a trabalhar com a modalidade oral e, quando o fazem, a atenção voltase a atividades que apenas usam a modalidade falada como, por exemplo, "conversas com colega", "leitura em voz alta", "discussões em grupo" e "correção de exercícios feita oralmente". Cyranka e Magalhães (2012) esclarecem que "conceber oralidade como prática social na modalidade falada da língua significa, para o ensino, usar os gêneros 


\section{Revista do SELL \\ v. 6 , no. 3 \\ ISSN: $1983-3873$}

textuais orais, selecionados a partir das reflexões do corpo docente, contemplando, de fato, uma proposta de prática social e discursiva" (CYRANKA; MAGALHÃES, 2012, p. 62).

Em se tratando de propostas pedagógicas, sistematizar o ensino da oralidade envolve a interação com textos por meio de escuta, produção oral e reflexão linguística. Mais do que isso, é compreender que por meio da língua falada poderíamos chegar à língua escrita, usando um percurso mais proveitoso, já que partiríamos do que o aluno conhece para domínios que ele desconhece. Poderia permitir, também, que os educandos construíssem conhecimentos e conceitos sobre a linguagem, sobre as relações entre fala e escrita, entre outros.

Ainda assim, mesmo com o avançar nas pesquisas linguísticas, a oralidade ainda vem ganhando contornos controversos no ensino de língua portuguesa. Para Antunes (2003), por exemplo, ainda se constata:

[...] uma quase omissão da fala como objeto de exploração no trabalho escolar; essa omissão pode ter como explicação a crença ingênua de que os usos orais da língua estão tão ligados à vida de todos nós que nem precisam ser matéria de sala de aula [...].

[...] uma equivocada visão da fala, como o lugar privilegiado para a violação das regras da gramática. De acordo com essa visão, tudo o que é erro na língua acontece na fala e tudo é permitido, pois ele está acima das prescrições gramaticais; não se distingue, portanto, as situações sociais mais formais de interação que vão, inevitavelmente, condicionar outros padrões de oralidade que não o coloquial [...]. (ANTUNES, 2003, p. 24-25)

Como observado acima, é possível perceber que a oralidade está sempre atrelada ao lugar do "caos" e da informalidade, "enquanto a escrita é estruturalmente mais organizada e, consequentemente, prestigiada" (GARCIA e ORANGES, 2016, p. 170). Afirmações como essas, ecoam nos espaços escolares e acabam por ignorar que a oralidade está situada em diferentes níveis da esfera social e assume, portanto, papel fulcral nas interações humanas, com maior frequência, inclusive que a escrita.

O primeiro passo para o trabalho consciente com a oralidade em sala de aula é o professor reconhecer a importância da modalidade oral da língua como instrumento de trabalho e, mais do que isso, reconhecer que embora o aluno chegue na escola "falando" sua variedade, o trabalho com a oralidade tem, dentre um de seus objetivos, garantir que os educandos se apropriem de outras variedades, inclusive a norma culta e utilize a oralidade em diferentes situações de comunicação. A partir disso, se desprender do preconceito tão arraigado de que sua atuação docente deve se pautar na modalidade escrita. 


\section{Revista do SELL \\ v. 6 , no. 3 \\ ISSN: $1983-3873$}

Da mesma maneira que a escrita, a modalidade oral também sofre pressões sociais, sendo necessário que quem a use, saiba utiliza-la de maneira consciente e, sobretudo, adequada as situações de comunicação diversas. Nesse aspecto, é dever do professor colocar a oralidade como um caminho para se chegar ao texto escrito, mas não com atividades de retextualização, e sim como um diálogo entre as duas modalidades.

Outro ponto importante para consolidar o ensino da oralidade é reconhecer a fala e escrita não como modalidades dicotômicas. As diferenças entre fala e escrita, conforme aponta Marcuschi (2005), devem ser definidas pelo uso e não pelo sistema. Existe um continuum (MARCUSCHI, 2005) muito sutil entre as duas modalidades a ponto que as semelhanças entre elas se sobrepõem às diferenças, tanto em aspectos linguísticos quanto sociocomunicativos.

Por fim, cabe ao professor mostrar aos discentes a grandiosidade do processo que envolve usos efetivos da língua, seja esse oral ou escrito. Ainda, é missão dos docentes ensinar seus alunos à adequar-se, conforme já falamos, as mais diversas situações sociocomunicativas que lhes são impostas.

\section{O ENSINO DA ORALIDADE: O QUE DIZEM OS PARÂMETROS CURRICULARES NACIONAIS}

Os Parâmetros Curriculares Nacionais (doravante PCN) (1998), publicados há quase duas décadas, têm como objetivo primordial sistematizar referências para o ensino em âmbito nacional, respeitando as especificidades regionais e das diferentes áreas. Os PCN relembram a relevância de desenvolver um trabalho que preze pelo uso da linguagem, nas diferentes instâncias, com intuito de viabilizar o domínio ativo discurso nos diferentes espaços de comunicação, de modo a garantir e ampliar as possibilidades de inserção e participação social do discente no exercício da cidadania.

Assim, com vistas ao trabalho com a língua como objeto de ensino, nota-se que, no documento em questão, os conteúdos de língua portuguesa organizam-se em dois enfoques: (i) o uso da língua oral e escrita, em que os gêneros da oralidade se articulam na prática de escuta e na produção de textos orais; e (ii) a reflexão sobre a língua e a linguagem, que prevê a prática de análise linguística. Dessa maneira, a escola, conforme prega o PCN, deve se configurar como um espaço em que o aluno seja capaz de promover situações didáticas: 


\section{Revista do SELL \\ v. 6 , no. 3 \\ ISSN: $1983-3873$}

Ao utilizar a linguagem na escuta e produção de textos orais e na leitura e produção de textos escritos de modo a atender a múltiplas demandas sociais, responder a diferentes propósitos comunicativos e expressivos, e considerar as diferentes condições de produção do discurso (BRASIL, 1998, p. 32)

Para isso, faz se necessário apresentar a concepção de linguagem presente no PCN que entende a língua oral como:

Ensinar língua oral deve significar para a escola possibilitar acesso a usos da linguagem mais formalizados e convencionais, que exijam controle mais consciente e voluntário da enunciação, tendo em vista a importância que o domínio da palavra pública tem no exercício da cidadania. Ensinar língua oral não significa trabalhar a capacidade de falar em geral. Significa desenvolver o domínio dos gêneros que apoiam a aprendizagem escolar de Língua Portuguesa e de outras áreas e, também, os gêneros da vida pública no sentido mais amplo do termo (BRASIL, 1998, p. 67-68)

Observando o exposto, trabalhar oralidade, ou melhor, ensinar a língua oral não implica ensinar o aluno a falar, pelo contrário, é oportunizar o domínio de alguns gêneros orais para ampliar a competência comunicativa do aluno. Além do mais, o ensino dessa modalidade é capaz de dirimir as dicotomias apresentadas por Marcuschi (2001, p. 27), "dicotomias perigosas", tão fortemente apontadas na escola e que acabam por restringir o uso oral ao campo da informalidade e do improviso.

Desse modo, o desenvolver da oralidade no âmbito escolar requer uma aproximação com os gêneros que fazem parte do dia a dia dos alunos, assim é papel do docente inserir o educando nas mais diferentes situações comunicativas na qual seja possível o aluno desenvolver a modalidade oral da língua, coadunando, sobretudo, com o que apregoa o PCN (1998). Com isso, quando o aluno faz uso dessa prática à aprendizagem assume seu caráter social e interativo por meio da linguagem.

Desse modo, os discentes passam por um processo de transição entre aquilo que eles já sabem com o que ainda irão aprender e quando vão aprender, já que a criança quando chega a escola já tem um domínio satisfatório da competência discursiva expressada por meio da fala, restando, então, a necessidade de ajustar esta comunicação diária às necessidades cotidianas, para comunicar-se em interações que envolvem relações sociais complexas e do dia a dia.

A esse respeito, o PCN completa:

Já que os alunos têm menos acesso a esses gêneros nos usos espontâneos da linguagem oral, é fundamental desenvolver na escola, uma série de atividades de escuta orientada que possibilitem a eles construir progressivamente, modelos apropriados ao uso do oral nas 


\section{Revista do SELL}

v. 6 , no. 3

ISSN: $1983-3873$

circunstancias previstas (BRASIL, 1998, p. 68).

Com base nisso, reitera-se a importância do ensino de Língua Portuguesa baseado em gêneros discursivos, orais e textuais, uma vez que são ferramentas indispensáveis para a construção de conhecimentos relativos às manifestações reais da linguagem em vias sociais. É importante esclarecer, também, que o intuito de desenvolver a oralidade do aluno, não se deve priorizar apenas um nível de fala culto. A escola forma cidadãos, portanto, o educar do aluno é para a vida, isso é, para as ações que desempenham fora dos muros das escolas, e dentro de situações em que são convidados a exercer seu papel de cidadão.

Nas inúmeras situações sociais do exercício da cidadania que se colocam fora dos muros da escola à busca de serviços, as tarefas profissionais, os encontros institucionalizados, a defesa se seus direitos e opiniões- os alunos serão avaliados (em outros termos, aceitos ou discriminados) à medida que forem capazes de responder a diferentes exigências de fala e de adequação as características próprias de diferentes gêneros orais (BRASIL, 1998, p. 25).

Para que haja um aproveitamento significativo do ensino, o professor deve organizar, sobretudo, situações de aprendizagem que perpassem as fronteiras escolares, ministrando aulas dinâmicas e que se relacionam com a realidade de seus alunos, ao contrário as aulas ficarão desconectadas e, portanto, monótonas. Em relação aos princípios organizacionais que regem os conteúdos de ensino, o PCN (1998) deixa explicito que devem ser selecionados conforme a possibilidade de apropriação, por parte do sujeito, que deverá transformar os conteúdos "em conhecimento próprio, por meio da ação sobre eles, mediado pela interação com o outro" (BRASIL, 1998, p. 33). Daí urge a relevância de se proceder uma abordagem que possibilite ênfase a fala dos alunos.

"A importância do ensino da oralidade perpassa vários saberes e está imbricado em inúmeros outros conhecimentos que os alunos precisam ampliar enquanto passam pela formação escolar" (GARCIA, 2016, p. 10). Por outro lado, o documento em questão alerta sobre o tratamento controverso que dá a escola a oralidade, já que, na maioria das vezes, o trabalho com a oralidade tem como fim apenas um exercício escrito e leitura em voz alta. Não significa dizer que essas situações não sejam relevantes para os alunos, porém se o que se busca é a ampliação da competência linguístico-discursiva dos educandos, é preciso, desse modo, que sejam oferecidos meios para que os alunos possam perceber as diferentes exigências do uso do gênero oral e a necessidade de 


\section{Revista do SELL \\ v. 6 , no. 3 \\ ISSN: $1983-3873$}

adequação aos diferentes espaços e diferentes gêneros que exijam o uso da oralidade, de modo formal ou informal.

Para completar, é preciso retomar que os avanços nos estudos linguísticos sobre o ensino da língua materna contribuíram para uma reflexão acerca da necessidade de uma revisão das práticas de ensino e aprendizagem da língua materna. Nessa linha de pensamento, Cavalcante e Melo (2006) já destacava que o uso da oralidade, nos livros didáticos, padecia de muitos problemas. É pensando nisso que esse trabalho, onze anos depois, vem buscar se há um declínio ou progresso em relação ao tratamento da oralidade nos livros didáticos. Os pesquisadores acima antes destacavam que:

Os autores de manuais didáticos, em sua maioria, não sabem onde e como situar o estudo da fala. Muitas vezes, os livros dão a impressão de que a fala figura apenas como curiosidade por parte dos autores dos livros didáticos. São recorrentes os exercícios que se limitam a atividades do tipo: "Converse com seu colega", ou "Dê a sua opinião", "Discuta em sala com o professor". (CAVALCANTE\& MELO, 2006, p. 182)

Pode-se afirmar, nesse sentido, que o PCN se apresenta como um suporte capaz de subsidiar as ações dos professores, mas figura, em sua maioria, como "enfeites de estantes", além de estarem distantes das discussões das ações pedagógicas. Sendo assim, é fulcral que os professores e coordenadores pedagógicos se guiem através dos Parâmetros Curriculares ou mais do que isso, tragam como foco de discussão, já que no que tange as possibilidades de efetivação do trabalho com a oralidade e, consequentemente, o desenvolvimento da competência comunicativa dos educandos, os PCNs trazem boas contribuições que podem ser aprimoradas.

As diretrizes estabelecidas pelos PCNs têm grande impacto na formação dos futuros profissionais da educação, guiando práticas pedagógicas e prezando pela inovação e criação de condições para que os alunos façam o uso da língua de maneira consciente e proveitoso, livre de preconceitos e amarras. Assim, o referido documento trabalha a oralidade a partir das considerações sobre o ensino de língua e o seu estrito papel na formação de um cidadão, socialmente pleno, considerando as diferenças culturais econômicas e níveis de conhecimento que serão mais acentuados a cada ano que o aluno avançar no caminho escolar. 


\section{Revista do SELL}

v. 6 , no. 3

ISSN: $1983-3873$

\section{APONTAMENTOS METODOLÓGICOS}

O livro didático é "uma importante ferramenta para o regente de qualquer disciplina, sendo instrumento decisivo sobre o que e como ensinar em sala de aula" (GARCIA; SILVA; ARAUJO, 2017, p. 9). Assim, considerando sua importância no processo pedagógico, buscamos analisar, para atingir o objetivo deste artigo, dois livros aprovados pelo PNLD/2017. Neles, buscamos investigar a abordagem que está sendo dado ao eixo oralidade e, consequentemente, aos gêneros orais e a relação entre oralidade-escrita.

Assim, esta pesquisa caracteriza-se como descritivo-bibliográfico e documental com abordagem qualitativa (GARCIA; SILVA; ARAUJO, 2017). O estudo em pauta selecionou o livro de Português do projeto Teláris (BORGATTO; BERTIN; MARCHEZI, 2015¹), Editora Ática, do 6ำ ano e, ainda, Língua Portuguesa da coleção Universos (PEREIRA; BARROS; MARIZ, 2015), organizado pela Editora SM, e também do 6ํa․ a escolha desses volumes não é aleatória, já que apesar dos avanços nas últimas décadas, as implicações decorrentes da correlação entre heterogeneidade linguística e oralidade e escrita, estão longe de se esgotar.

Para facilitar a análise desses materiais, foram estabelecidos alguns critérios para englobar as atividades voltadas para o ensino da oralidade, a saber:

(i) atividades de oralizaçãoda escrita;

(ii) atividades que estimulam a reflexão sobre o vocabulário, a variação linguística e as relações entre fala e escrita;

(iii) atividades que estimulem a produção de gêneros orais

(iv) atividades que priorizem a compreensão de gêneros conversa/discussão.

Dentro do primeiro item, serão consideradas as atividades de leitura em voz alta, dramatização, recitação de poesia, leitura em jogral, entre outros. Em (ii) interessa-nos apontar comparações entre variantes orais diferentes, comparação entre registros escritos e variantes orais, uso da escrita como apoio à produção oral e atividades de retextualização. No item (iii) observaremos as atividades que estimulem gêneros orais como: entrevistas, relatos pessoais, notícias ou reportagens em jornais falados, discurso de defesa, exposição oral, debates (seminários), entre outros.

${ }^{1} \mathrm{O}$ apresentado é o da edição disponível online, mas sua aprovação se deu no Programa Nacional do Livro Didático de 2017. 


\section{Revista do SELL}

v. 6 , no. 3

ISSN: $1983-3873$

Algumas ressalvas precisam ser feitas, como observado acima, no item (ii), apenas serviram como foco de analise as atividades acima apresentados, não nos interessa, para essa discussão, constatar as atividades que fazem reflexão acerca da variação linguística, sem que estabeleçam diálogos com as questões que envolvam a fala e a escrita. Só o tratamento da variação linguística, acentuando que a língua é heterogênea, não garante, com autonomia a oralidade. Enquanto no item (iv) investiga-se constatar a quantidade de atividades que são restritas a produção de conversação e discussão, mesmo que se trate de gêneros orais, não implica que a oralidade esteja sendo tratada de maneira plena, uma vez que a discussão e conversação implicam sempre responder questões escritas de algum texto escrito a qual os alunos são convidados a discutir.

\section{ANÁLISE DOS MATERIAIS DIDÁTICOS}

O estudo em questão envolveu a análise de dois materiais didáticos, conforme apontados acima, destinados aos alunos do $6^{\circ}$ ano (Ensino Fundamental II). Ambas as obras passaram pelo crivo e foram aprovadas para comporem a coleção dos livros didáticos do Programa Nacional do Livro Didático 2017-2020. Antes de adentrarmos a análise dos materiais, retomaremos os estudos de Marcuschi (1997), que analisou alguns materiais didáticos, entre 1978 e 1997, e verificou que as atividades voltadas para a oralidade são muito reduzidas, haja vista o espaço destinado a elas "raramente supera o ridículo percentual de $2 \%$ no cômputo geral de páginas" (MARCUSCHI, 1997, p. 45).

Em nota de rodapé, ainda neste estudo, Marcuschi (1997) acrescenta "um livro com 200 páginas não atinge em geral um total de 04 a 05 páginas inteiras sobre a fala, somando-se todos os momentos em que a fala é analisada ou a ela se faz referência" (MARCUSCHI, 1997, p.45). Rojo (2003), traça o perfil de 37 coleções didáticas diferentes, totalizando 148 livros didáticos de Língua Portuguesa, avaliados pelo PNLD 2002, referente aos quatro últimos anos do ensino fundamental. A pesquisadora consagra que apenas $20 \%$ do material recebeu avaliação positiva em relação ao trabalho com a oralidade.

Nas palavras da pesquisadora,

no que concerne às atividades de compreensão e de produção de textos orais é esse o domínio em que há menor clareza, por parte de autores e editores, sobre como ensinar e sobre como se aprende. Apenas $23 \%$ das coleções realizam algum tipo de trabalho adequado quanto a essas atividades. (ROJO, 2003, p.92) 


\section{Revista do SELL}

v. 6 , no. 3

ISSN: $1983-3873$

Dando um salto, na dissertação de Nery (2008), foram analisadas duas coleções voltadas aos anos finais do ensino fundamental, o objetivo era atestar a abordagem atribuída ao ensino da oralidade e, também, sugerir novos exercícios envolvendo oralidade que poderiam ter sido inseridos no material em análise. Segundo a pesquisadora, "os momentos em que a oralidade é tomada como objeto de ensino mostram-se bastante reduzidos" (NERY, 2008, p. 61).

Após destacar algumas pesquisas que já se debruçaram em investigar os materiais didáticos quanto ao seu domínio da oralidade, nesta pesquisa, quase dez anos depois da publicação da dissertação de Nery (2008) e vinte anos depois da publicação de Marcuschi (1997), pretende-se verificar, nos materiais analisados, se estes alinharam seus pensamentos aos estudos linguísticos contemporâneos, apresentando, contudo, um progresso ou se ainda estão distante de estabelecer um diálogo coerente com as pesquisas de linguística moderna, verificando um declínio do tratamento da oralidade nos materiais didáticos.

O primeiro livro a ser analisado do Projeto Teláris - Português (BORGATTO; BERTIN; MARCHEZI, 2015) está separado em quatro unidades, sendo elas:

Tabela 1 - Unidades do livro Português do Projeto Teláris

\begin{tabular}{c|c} 
UNIDADE 1 & Contos de tradição oral \\
\hline UNIDADE 2 & Conto: imaginação e realidade \\
UNIDADE 3 & Relato pessoal e relato jornalístico \\
UNIDADE 4 & Defender ideias
\end{tabular}

Cada unidade é composta de dois capítulos, totalizando, portanto, 8 capítulos. Enquanto isso, o segundo livro é Língua Portuguesa da coleção Universos (PEREIRA; BARROS; MARIZ, 2015) é separado, também, em 4 unidades, contendo 3 subunidades cada unidade, a saber:

Tabela 2 - Unidades do livro Língua Portuguesa coleção Universos

\begin{tabular}{l|c} 
UNIDADE 1 & A cultura nossa de cada dia \\
\hline UNIDADE 2 & Por um meio ambiente por inteiro \\
UNIDADE 3 & Olhos e ouvidos na telona \\
UNIDADE 4 & É campeão
\end{tabular}




\section{Revista do SELL}

v. 6 , no. 3

ISSN: $1983-3873$

Como destacados em aspectos metodológicos, observaremos os livros selecionados a partir de critérios pré-definidos como demonstra a Tabela 3 abaixo:

Tabela 3- Total de atividades por dimensão de ensino da oralidade nos livros didáticos selecionados

\begin{tabular}{c|c|c}
\cline { 2 - 3 } & LIVRO 1 & LIVRO 2 \\
\hline DIMENSÕES CONTEMPLADAS & QTD & QTD \\
\hline ORALIZAÇÃo DO TEXTO ESCRITO & 8 & 8 \\
\hline REFLEXõES SOBRE VARIAÇÃo LINGÚSTICA, VOCABULÁRIO E RELAÇÕES FALA E ESCRITA & 10 & 4 \\
\hline ATIVIDADES QUE ESTIMULEM A PRODUÇÃo DE GÊNEROS ORAIS & 10 & 4 \\
\hline ATIVIDADES QUE PRIORIZEM A COMPREENSÃO DE GÊNEROS CONVERSA/DISCUSSÃo & 40 & 32 \\
\hline
\end{tabular}

Observando o exposto, é possível afirmar que o livro 1 (BORGATTO; BERTIN; MARCHEZI, 2015) priorizam mais as dimensões que contemplam o trabalho com a oralidade. Em contrapartida, o segundo material (PEREIRA; BARROS; MARIZ, 2015) nem tanto. O número de atividades é bastante restrito, o que, sem dúvidas, constitui um sinal de retrocesso para o presente material, visto que o 6ªno é o estágio que o aluno sai do Fundamental I, com algumas carências, sendo necessário aprimorar, dentre todas as atividades linguísticas, o trabalho com a oralidade, de modo que a interferência entre a fala e a escrita, por exemplo, possam ser sanadas e aprimorar a competência linguísticas dos estudantes.

Ambos os materiais apresentam três atividades que preconizam a oralização do texto escrito. Esta dimensão, tal como a compreendemos, é a interseção entre o tratamento da oralidade e o da leitura, uma vez que envolve tanto o desenvolvimento da fluência da leitura, fundamental para a presente série, quanto de algumas habilidades típicas da comunicação oral, mas não deve ser restringir a isso. Neste sentido, os materiais não apresentam um número exacerbado deste aspecto, priorizando outros pontos relevantes do tratamento da oralidade. Dentre as atividades de oralização do texto escrito estão: leitura dramatizada, leitura jogralizada, recitação de poesia, leitura em voz alta e leitura de entrevista. 


\section{Revista do SELL \\ v. 6 , no. 3 \\ ISSN: $1983-3873$}

Figura 1: Exemplos de atividades extraídas dos livros didáticos para ilustrar o item (i) oralização do texto escrito

\footnotetext{
$\rightarrow$ Durante a leitura

A estrutura básica de uma entrevista è o par pergunta-resposta. No texto que vocè vai ler, 0 entrevistador (quem pergunta) è o jornalista Fernando Fernandes, e a entrevistada (quem responde) é a jogadora de futebol Marta.

Você e os colegas vão fazer a leitura da entrevista em voz alta, revezando-se nos papéis de entrevistador e entrevistada. Para tanto, a entrevista foi dividida em onze partes, e os pares de pergunta. -resposta foram numerados de 1 a 33.

Aqui a conversa é diferente

Leia as instruçôes para realizar a atividade

1. A turma deve se dividir em duplas; cada uma ficará responsável por ler uma das onze partes da entrevista. Se houver mais duplas do que partes do texto. os grupos devem se revezar na leitura.

Depois de definida a parte que será lida por sua dupla, combine com o colega quem lerá as falas de Marta e quem fará o papel do ornalista.

3. Antes da leitura coletiva, leia silenciosamente sua parte ao menos duas vezes, procurando compreender tudo o que foi lido.

4. No momento da leitura coletiva, fique atento ao têrmino da leitu. ra feita pela dupla anterior, para que não haja um longo silêncio entre uma parte e outra.

Fonte: Língua Portuguesa - coleção Universos (PEREIRA; BARROS; MARIZ, 2015)
}

๑ Prática de oralidade

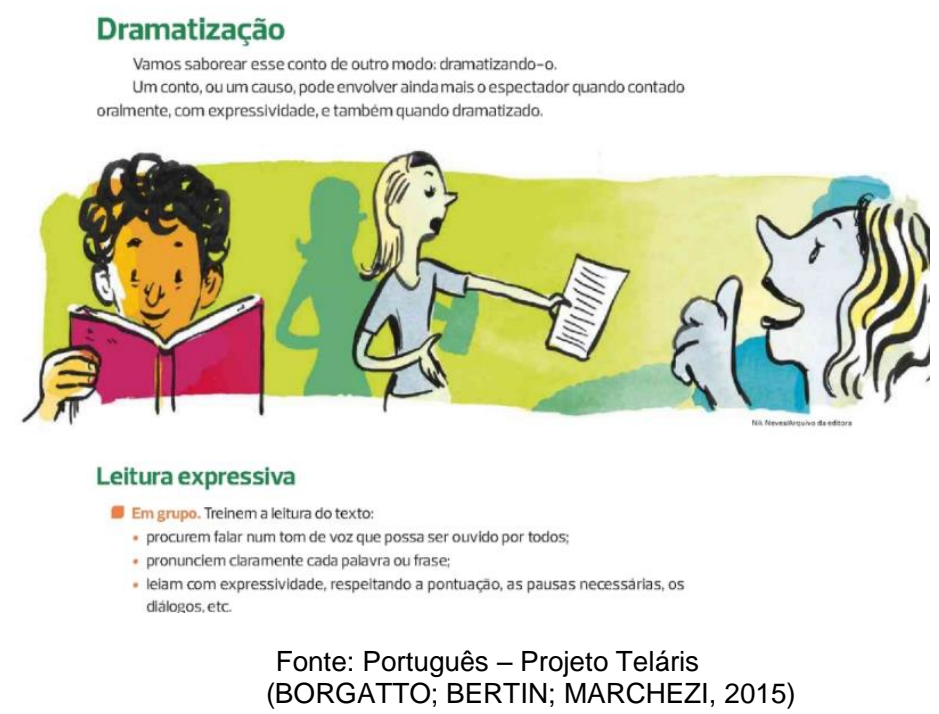

Nesse tipo de atividade, podemos observar uma atividade conjunta, já que, conforme destacado acima, o aluno, ao mesmo tempo, pratica a leitura e a oralidade. Assim, ela desenvolve a fluência da leitura e interage com os gêneros escritos, aprende, também, a se valer de recursos expressivos importantes, tais como controlar a voz, ritmo, usar gesticulações e expressão facial para causar o efeito pretendido ao público. O que é importante destacar é o papel do professor na tentativa de proporcionar um trabalho dialogado e de interseção entre essas duas dimensões do escrito para oral. Priorizar atividades como essas, não é o caso dos materiais estudados, não implica que o tratamento da oralidade tem sido feito de maneira efetiva.

Em relação ao segundo critério de análise (ii) reflexões sobre variação linguística, vocabulário e relações fala e escrita, o livro 1 despontou com o total de 10 atividades, enquanto o segundo material apresentou 04 atividade em que o trabalho com a variação linguística pudesse ser relacionado com o aspecto da oralidade. Desse modo, quando pensasse em determinar a oralidade como eixo do trabalho pedagógico isto implica definirmos quais as diferentes dimensões desse ensino. Nesse sentido, compreender a reflexão sobre a fala e suas variações é, sem dúvidas, um aspecto relevante a ser explorado nos compêndios. Sgarbi (2008, p. 168) acrescenta que "estudar, ensinar e aprender uma língua, em uma perspectiva sociolinguística, são tarefas para aqueles que 


\section{Revista do SELL \\ v. 6 , no. 3 \\ ISSN: $1983-3873$}

conseguem perceber a dinamicidade a que ela está exposta e derrubar o mito de que somente a língua padrão é a única forma correta de pensar esse ensino/aprendizagem".

Das 10 atividades acima mencionadas dentro do segundo critério de análise do Livro 1, temos atividades de retextualização, comparação entre registros escritos e variantes orais, comparação entre diferentes variantes orais e reflexão não dicotômica entre fala e escrita. Nesse quesito, o livro apresenta um progresso em relação ao material 2, já que com vistas a acabar com o preconceito linguístico, o presente material conduz os alunos a pensar e produzir descrições das diferentes formas dialetais e, também, refletir sobre os fatores que provocam as diferenças nesses modos de falar.

Figura 2 - Exemplo de atividade extraída dos livros para ilustrar o item (ii) reflexões sobre variação linguística, vocabulário e relações fala e escrita

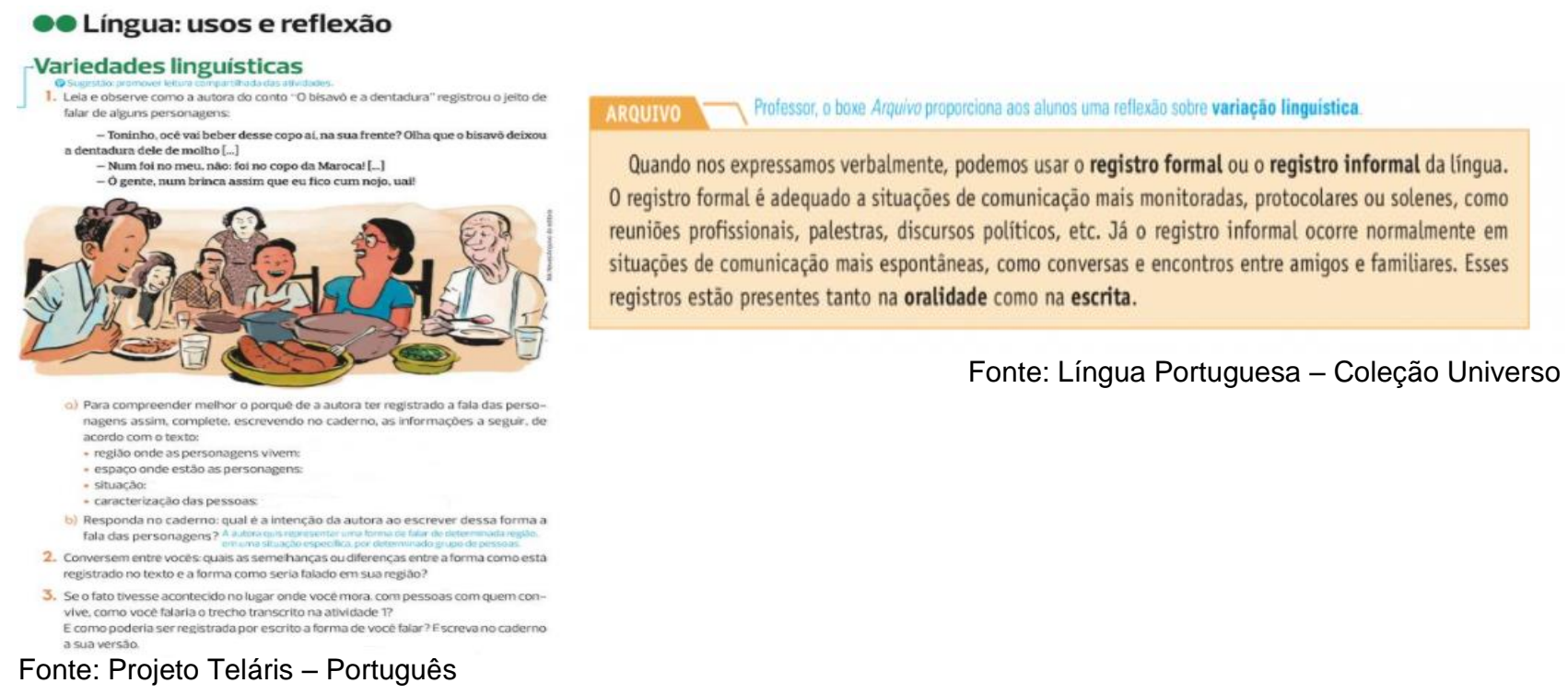

Nas figuras acima, temos à esquerda uma reflexão com atividades sobre a variedade linguística e, a direita, um informativo para que o professor possa ampliar a competência comunicativa do aluno sobre a variedade linguística e, tal tipo de reflexão, quando feito de modo paralelo ao debate sobre as relações entre oralidade e escrita como é o caso acima, acabam permitindo que os alunos percebam a dinâmica da língua como algo heterogêneo e, mais do que isso, que a fala é tão importante quanto a escrita e que também é regida por regularidades. Outro aspecto importante da atividade (à esquerda) é que ela permite que os alunos entendem que diferentes modos de falar e que tais diferenças são marcas identitárias de grupos, não constituindo, portanto, erros de língua. Para isso, a atividade 2, acima, convida os alunos a "Conversar entre os colegas 


\section{Revista do SELL \\ v. 6 , no. 3 \\ ISSN: $1983-3873$}

quais são as semelhanças e diferenças entre a forma com que está registrado no texto e a forma como seria falado em sua região?”.

Ainda, a atividade 3, é solicitado aos alunos que: "Se o fato tivesse acontecido no lugar onde você mora, com as pessoas que você convive, como você falaria o trecho transcrito na atividade 1 ? E como poderia ser registrado por escrito a forma de você falar? Escreva no caderno a sua versão". Como podemos observar, a proposta da atividade é interessante, porque reforça a necessidade do aluno de pensar a diferença dialetal observando o que seria comum no seu dia a dia. Uma pequena ressalva deve ser feita, já que não proporciona aos alunos a análise de textos orais na modalidade oral, apenas apresenta-se um texto "transcrito", solicitando que eles façam o mesmo em relação a como eles falaria o trecho da atividade 1. Nesse espaço, o material deixa de oferecer algo mais coerente com a modalidade oral, visto que poderiam ser solicitados atividades que envolvessem gravações de fala do cotidiano das famílias dos alunos e, posteriormente, uma análise em conjunto com os alunos.

Figura 3 - Exemplo de atividade extraída dos livros para ilustrar o item (ii) reflexões sobre variação linguística, vocabulário e relações fala e escrita

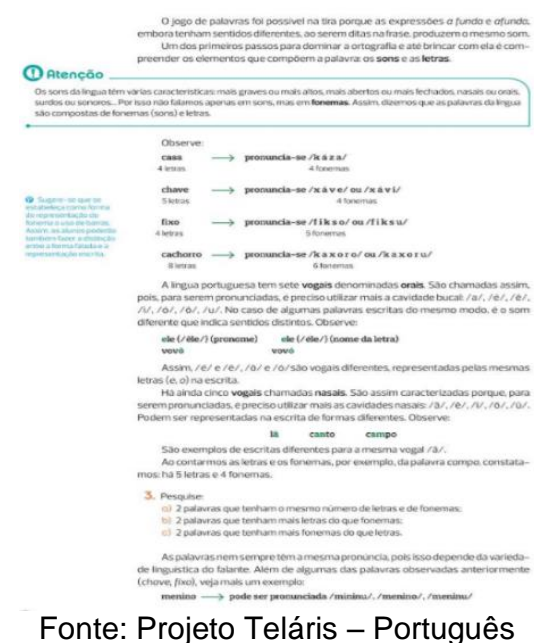

Fonte: Projeto Teláris - Português

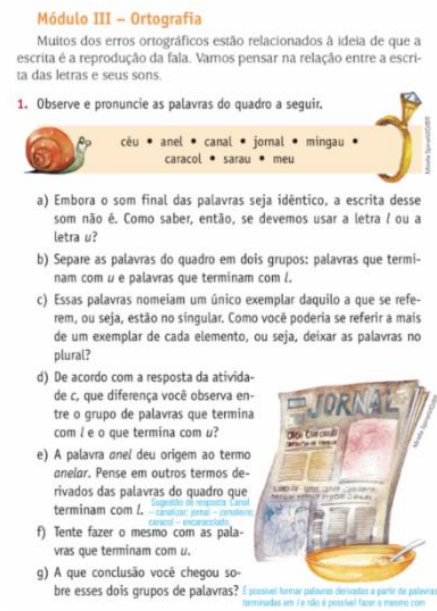

Fonte: Língua Portuguesa - Coleção Universos

Um fato positivo, de ambos os materiais, é a reflexão proposta pelos materiais sobre a relação entre fala e escrita, conforme mostra a Figura 3. Acima, temos em destaque que uma das formas de compreender a ortografia de maneira plena, é entender a relação intrínseca entre fala e escrita. Dessa maneira, no primeiro livro, os autores apresentam as sete vogais orais e as cinco nasais e convidam os alunos a compreender a diferença entre grafemas e fonemas. Dessa maneira, os autores apresentam as sete vogais orais e as cinco nasais e convidam os alunos a compreender a diferença entre 


\section{Revista do SELL \\ v. 6 , no. 3 \\ ISSN: $1983-3873$}

grafemas e fonemas. Um trabalho consciente por parte do professor é fundamental para que os desvios ortográficos de natureza fonológica (GARCIA, 2016) possam com a prática, serem repensados e não mais relegados ao domínio do erro de língua. As atividades para sistematizar essa relação são apresentadas em seguida e com questões pertinentes que fazem com que os alunos percebam o quão sutil é essa relação da oralidade com a escrita e que, de que maneira, ela influência na ortografia.

No segundo material, não há uma parte introdutória como o primeiro, apenas uma nota que ressalta que muitos erros ortográficos estão relacionados com a ideia de que a escrita é à reprodução da fala e, na sequência, os educandos são convidados a refletir sobre os pares de palavras que são pronunciadas com / $\mathrm{u} /$ no final, mas ora grava-se com "l" ora com "u". As perguntas que seguem convidam os alunos a refletir a semelhança entre a fala e a escrita e perceberem que não há nada que justifique a troca das grafias a não ser a convenção ortográfica e uma pitada histórica por traz de algumas palavras. Numa segunda oportunidade o livro 2, traz outra reflexão sobre essa relação só que o foco recaí sobre as várias representações grafêmicas do fonema $/ \mathrm{s} /$.

Desse modo, os livros mantem um diálogo coerente com que propõe, por exemplo, Dolz e Schneuwly (2004) já que "para uma didática em que se coloque a questão do desenvolvimento da expressão oral, o essencial não é caracterizar o oral em geral e trabalhar exclusivamente os aspectos de superfície da fala, mas, antes, conhecer diversas práticas orais de linguagem e as relações muito variáveis que estas mantêm com a escrita". Apoiar essas atividades, que englobem a discussão entre fala e escrita, é importante para que o educando compreenda de que maneira podemos usar a escrita como apoio para a produção oral e vice-e-versa. As crianças podem aprender de maneira significativa a fazer isso ao exporem um determinado conhecimento em público, em que é necessário um planejamento escrito anterior para após proferi-lo.

No item (iii) estão as atividades que estimulem a produção de gêneros orais, dentre as atividades encontras, observamos que o livro 1 apresenta um número maior de atividades, um pouco mais que o dobro do livro 2. Um ponto positivo em relação ao primeiro material analisado (BORGATTO; BERTIN; MARCHEZI, 2015) é a presença de diferentes gêneros orais em que os alunos são convidados a produzir, dentre eles 0 debate estruturado que aparece duas vezes em dois momentos diferentes do livro. Neste material, ainda podemos encontrar os gêneros: entrevista, relato pessoal, jornal falado, jogral e etc. $O$ segundo material também apresenta atividades interessantes, mas em 


\section{Revista do SELL \\ v. 6 , no. 3 \\ ISSN: $1983-3873$}

pequenas quantidades. Por exemplo, a presença do gênero entrevista, aparece timidamente, com uma explicação breve e pouco articulada com as relações entre oralidade e escrita. Além dele, também encontramos os gêneros relato pessoal, narração futebolística e "sarau".

Figura 4 - Exemplo de atividade extraída do livros para ilustrar o item (iii)
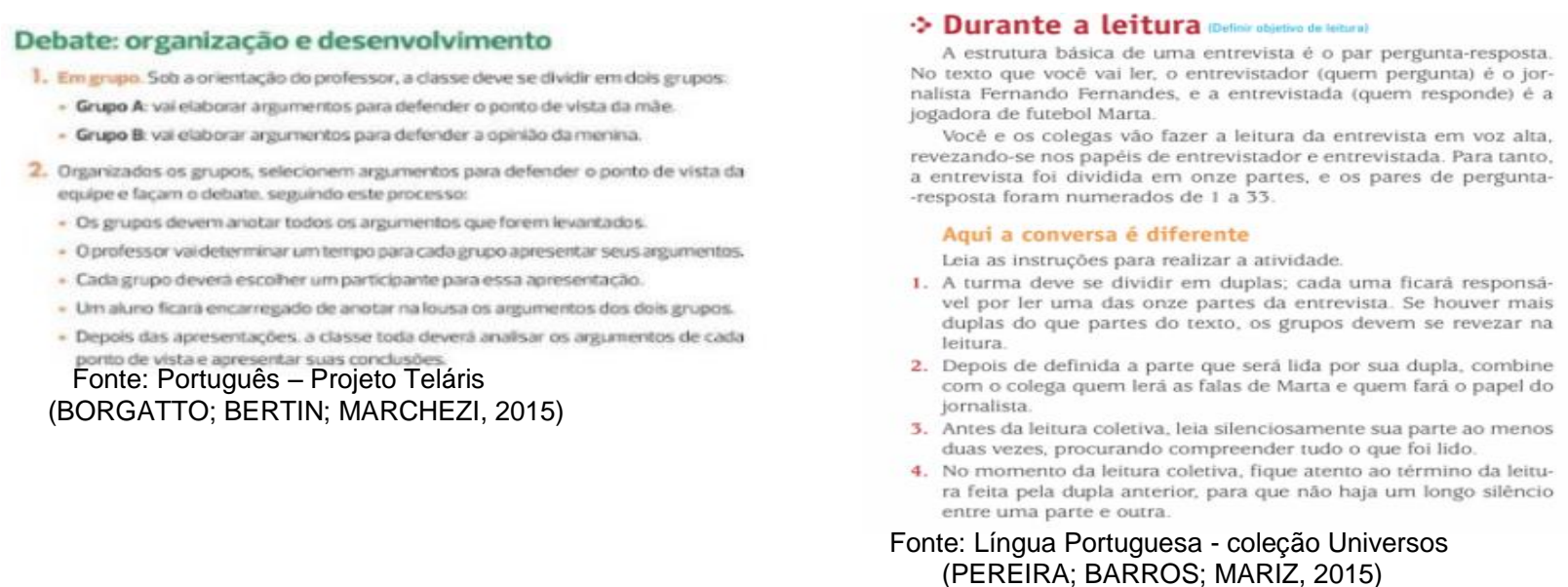

A produção e compreensão de textos orais em contextos significativos são fundamentais, já que "os gêneros orais sejam produzidos e escutados em atividades autênticas a fim de que se privilegiem as atividades de análise linguística dos gêneros orais, o que proporcionaria a ampliação dos conhecimentos de linguagem oral" (MAGALHÃES, 2007, p. 61). Neste caso, precisamos desenvolver habilidades bastantes variadas, sendo estas em relação ao desenvolvimento de atitudes de respeito ao que o outro está falando - quando trata-se do gênero debate, por exemplo - monitoramento do seu próprio tempo de fala, escuta atenta ao que o outro diz, até conhecimento e habilidades relativos à forma composicional de gêneros complexos, como seminários, notícias orais ou debates regrados, ou mesmo conhecimentos relativos aos papéis desempenhados pelos envolvidos em uma determinada em uma determinada situação de interação, como em um júri.

$\mathrm{O}$ item (iv) contempla as atividades orais que envolvem os gêneros conversa/discussão. Como é possível notar, nos livros didáticos, a conversa/discussão ocupa um grande espaço nas atividades para o ensino do oral, mesmo que isso não seja feito de forma consciente pelo professor. Nesse interim, observa-se que a conversa é sempre sobre o tema dos textos a serem lidos ou já lidos, quando não, conversa-se sobre interpretação de textos lidos e, ainda, para aprender mais sobre o gênero em questão. 


\section{Revista do SELL \\ v. 6 , no. 3 \\ ISSN: $1983-3873$}

Outra maneira interessante da utilização da conversa é na realização e avaliação de atividades que já forma avaliadas.

A grande quantidade de ocorrências dessa natureza apresenta um progresso para o material didático, uma vez que evidencia uma concepção de aprendizagem como uma atividade social, como construção coletiva, em que os discentes aprendem na interação com os outros. Afinal, a criança também ressignifica saberes com a pratica coletiva, construindo para formação de um repertório de saberes que, certamente, contribui para formação do aluno como cidadão, bem como gerar conteúdo para práticas de escrita mais dialogadas.

\section{CONSIDERAÇÕES FINAIS}

Conclui-se que trabalhar a oralidade na sala de aula privilegiando as práticas discursivas é antes de tudo fazer o educando vivenciar os diferentes usos da língua. Levá-lo, portanto, a reflexão acerca do uso e ensinando-o a respeitar as variedades linguísticas e desmistificar a ideia de que a fala é lugar do caos, enquanto a escrita é planejada e bem estruturada. Outro ponto importante observado com as atividades dos livros que propõe a reflexão da variedade linguística do aluno, é que o docente pode aproximar-se e interagir de maneira mais respeitosa com seus alunos. Constamos ainda que, ambos os livros apresentam progressos, mesmo que de maneira pequena.

Geraldi (2002) relembra-nos que a linguagem é vista como o lugar da interação humana, pois é por meio dela que o sujeito que fala prática ações e age sobre o ouvinte. Dolz \& Schneuwly (2004) consideram a oralidade como realidade multiforme, englobando não apenas aspectos fônicos, fonológicos, de entoação, mas também explorando lugares mais amplos do oral, como a própria materialidade do texto oral, seu enunciador, seu lugar de enunciação. Do mesmo modo, os Parâmetros Curriculares Nacionais reiteram a importância de a modalidade oral ser enfatizada pela escola, mesmo se tratando de um gênero inerente à condição humana, o que revela não ser um grande avanço considerados pelas coleções didáticas analisadas em nossa pesquisa.

A análise realizada permitiu entrever que as atividades contempladas nesses materiais didáticos não atendem à crítica, de modo que vão de encontro às orientações dos documentos que norteiam o ensino de língua portuguesa, tanto no que tange à produção quanto à compreensão dos gêneros orais em diferentes instâncias de uso. $\mathrm{O}$ 


\section{Revista do SELL \\ v. 6 , no. 3 \\ ISSN: $1983-3873$}

objetivo das atividades que envolvem a oralidade na sala de aula, segundo Marcuschi (2005), é possibilitar que os alunos percebam a riqueza que envolve o uso efetivo da língua como um patrimônio maior do qual não se deve abrir mão, reiterando a importância e o desafio de lidar com as variações linguísticas. De maneira geral, mesmo com os pequenos avanços, ainda se observa que os autores de livros didáticos têm dificuldades em situar o estudo da fala no livro didático.

Assim, revelamos a necessidade de: (i) compreender os pressupostos dos documentos oficiais que norteiam o ensino de Língua Portuguesa para, em seguida, (ii) realizar uma avaliação mais refinada quando selecionarem os livros didáticos para seus alunos e, especialmente, (iii) propor espaços para que os alunos, em sala de aula, possam contemplar o trabalho com os gêneros orais, complementando o que propõe 0 material didático. Além disso, é imprescindível (iv) a participação ativa do professor sobre o fato de que a modalidade oral, embora inerente ao sujeito como prática naturalizada pode e deve se constituir objeto de ensino nas instituições escolares, dado que compõe parte de um sistema linguístico.

\section{REFERÊNCIAS}

ASSUNÇÃO, M. A. L.; ARAUJO, M. J. F. S. ; RANGEL, R. I. S. ; BEZERRA, V. A. L. . Análise de textos dos alunos do 60 ano: principais desvios fonológicos.

Entrepalavras, v. 5, p. 117-139, 2015.

ANTUNES, Irandé. Aula de português: encontro \& interação. São Paulo: Parábola Editorial,2003.

BRASIL. Parâmetros curriculares nacionais: terceiro e quarto ciclos do ensino fundamental: língua portuguesa. Brasília: MEC/Secretaria de Educação Fundamental,1998.

BORGato, A. T; BERTIN, T; MARCHEZI, V. L. C.Português - 6o ano. Projeto Teláris. São Paulo: Ática, 2015.

CASTILHO, A. T. Estudos de língua falada:uma entrevista com Ataliba Teixeira de Castilho. Revista Virtual de Estudos da Linguagem-ReVEL. v. 3, n. 4, mar. 2005. Disponível em: <http://www.revel.inf.br/site2007/_pdf/4/entrevistas/revel_4_entrevista_ataliba_teixeira_de _castilho.pdf>. Acessoem: 10 jul. 2016. 


\section{Revista do SELL \\ v. 6 , no. 3 \\ ISSN: $1983-3873$}

Cyranka, L. F. M. ; MAGALHÃES, T. G.O trabalho com a oralidade/variedades

linguísticas no ensino de Língua Portuguesa. Veredas (UFJF. Impresso), v. 16, p. 5974, 2012.

FERREIRA, C; BARROS, F. P; MARIZ, L. Universos: língua portuguesa, 9ํano do ensino fundamental. 3. ed. São Paulo: Edições SM, 2015.

GARCIA, M. S.. Alçamento das vogais pretônicas /e/ e /o/: evidências da modalidade oral no texto escrito. Intertexto (Uberaba), v. 9, p. 1-16, 2016.

GARCIA, M. S.; ORANGES, C. S.Fala[ø] e Escreve [ø]: variação do rótico em posição de coda na escrita escolar de Uberaba/MG. Revista Entrepalavras, v. 7, p. 165-181, 2017.

GARCIA, M. S.; SILVA, M. C. A.; ARAUJO, S. S. F.Revisitando velhos percalços: a abordagem da variação linguística nos livros didáticos de Língua Portuguesa. Letra Magna (Online), v. 20, p. 1-20, 2017.

GERALDI, J. O texto na sala de aula. 3. ed. São Paulo: Ática, 2002.

LEAL, T.F; GOES, S (Orgs.). A oralidade na escola: a investigação do trabalho docente comofoco de reflexão. Belo Horizonte: Autêntica; 2012.

SILVA, E. C. L. da; LUNA, E. Á. dos A. Oralidade no livro didático: os primeiros passos de um longo caminho. REVISTA ENCONTROS DE VISTA, v. 2, p. 29, 2014.

MAGALHÃES, T. G. Oralidade na sala de aula: alguém "fala" sobre isso? Revista Instrumento: Revista de Estudo e Pesquisa em Educação. EDUFJF, v. 7/8, 2005/2006.

MARCUSCHI, L. A. Análise da conversação. São Paulo: Ática; 1986.

Oralidade e ensino de língua: uma questão pouco "falada". In: DionisioAP, Bezerra MA (Orgs.). Livro didático de português: múltiplos olhares. Rio de Janeiro:Lucerna; 2001a.

$2001 b$.

Da fala para a escrita: atividades de retextualização. São Paulo: Cortez;

. Gêneros textuais: definição e funcionalidade. In: DIONíSIO, Angela Paiva et al (org.). Gêneros textuais \& Ensino. Rio de Janeiro: Lucerna, 2003, p.19-36.

MARCUSCHI, L. A; DIONISIO, A. P (Org.). Fala e escrita. Belo Horizonte: Ceale; 2005.

MELO, C. T. V, CAVALCANTe, M. C. B. Superando os obstáculos de avaliar a oralidade. In: Marcuschi, L. A; Suassuna $L$ (Orgs.). Avaliação em língua portuguesa. Belo

Horizonte: Autêntica; 2006 


\section{Revista do SELL}

v. 6 , no. 3

ISSN: $1983-3873$

NERY, M. M. de A. Aspectos do tratamento da oralidade nos livros didáticos de Português no ensino fundamental: algumas sugestões. Dissertação (Mestrado em Descrição e Análise Linguísticas). -Universidade Federal da Bahia, Salvador, 2008, 75p.Disponível em:

<http://www.bibliotecadigital.ufba.br/tde_busca/arquivo.php?codArquivo=1568>. Acesso em: 10 mar. 2016.

SOARES, M. Concepções de Linguagem e o Ensino de Língua Portuguesa. In: História, perspectivas e ensino da língua portuguesa. São Paulo: Educ, 1998

SCHNEUWLY, B; DOLZ J, et al. Gêneros orais e escritos na escola. Trad. Roxane Rojo e GlaísSales Cordeiro. Campinas, SP: Mercado das Letras; 2004.

SGARBi, N. M. F. Q. Os eventos da oralidade no ensino de língua portuguesa.

Revista Trama. 2008;4(7):167-175.

SILVA, L. A. (Org.) A língua que falamos. Português: história, variação e discurso. São Paulo: Globo; 2005. 